\title{
Paediatric Health Professionals as Parent Educators: A Developing Role?
}

\author{
Jim Reeder \\ University of Brighton, UK \\ Jane Morris \\ University of Brighton, UK
}

\begin{abstract}
The purpose of this study was to develop an improved understanding of the perception of health professionals regarding the provision of information to parents of children with long-term disabilities. The aim was to generate new perspectives, inform debate, and to identify practical suggestions for health professionals. This study adopted a qualitative approach, guided by a phenomenological methodology. Seven health professionals, working within an Integrated Children and Young Person's Therapy Service of a single UK National Health Service (NHS) foundation trust, participated in semi-structured, in-depth interviews. The resultant data were analysed using a rigorous, systematic process of thematic content analysis. Two main themes were identified and discussed. Theme 1 was 'parent readiness for information'; with subthemes $1 \mathrm{~A}$ 'assessing parent readiness' and 1B 'developing parent readiness'. Theme 2 was 'role as information manager'. (It is acknowledged that a further theme 'relationship with parents' was identified; which will be presented and discussed in another article). The following conclusions were drawn. The health professional's role, as a provider of information to parents of children with disabilities, is evolving and may now be more helpfully described as that of a parent educator. It is suggested that this may involve a shift in focus from content/timing of information provision to the development of parents as learners. It is also suggested that it would be useful for health professionals to explore opportunities for practice-based initiatives to support the development of the skills required for this role.
\end{abstract}

Keywords: health information provision; parent education; readiness for information

${ }^{*}$ Corresponding Author: Jim Reeder, University of Brighton, School of Health Professions, Robert Dodd

Building, 49 Darley Road, Eastbourne, East Sussex, UKＢN20 7UR Email:jimreeder@nhs.net

Journal URL: http://e-learning.coventry.ac.uk/ojs/index.php/pblh

Reeder, J. and Morris, J. (2016) 'Paediatric health professionals as parent educators: A developing role?'. International Journal of Practice-based Learning in Health and Social Care, 4 (1), 40-54. doi:10.18552/ijpblhsc.v4i1.333

(C) $2016 \mathrm{Jim}$ Reeder and Jane Morris. This Open Access article is distributed under the terms of the Creative Commons Attribution Non-Commercial License 4.0 International License (http://creativecommons.org/licenses/by-nc/4.0/), which permits unrestricted non-commercial use, distribution, and reproduction in any medium, provided the original work is properly cited. 


\section{Introduction}

\section{Evolution of practice}

Traditionally, children with complex healthcare needs would have been supported by health professionals, employing a professional-centred model of care (Rosenbaum et al. 1998). In this model health professionals were responsible for determining the child's needs, before either carrying out a therapeutic intervention or instructing the parent to do so.

Driven by developments in UK government policy, culminating recently in the Children and Families Act (Great Britain Parliament 2014), and also by international health strategy (World Health Organization 2001), health professionals have increasingly been encouraged to adopt a more family-centred approach, empowering children and their families to assume a central role as 'partners' in a more collaborative process of goal setting and treatment provision (Kratz et al. 2009, Law et al. 2003, Tourigny, Chartrand, and Massicotte 2008). Indeed this is made explicit within the recently revised Health and Care Professions Council's standards of conduct, performance and ethics (Health and Care Professions Council 2016). Fundamental to this is the idea that the knowledge which a parent gains from the experience of living and caring for their child, is essential for determining their child's needs (Hanna and Rodger 2002, King et al. 2004).

This new role calls for notable added responsibility for parents, who already carry a significantly increased care-giving burden (Leiter et al. 2004). It therefore falls to health professionals to recognise the implications of any additional demands made (McCann, Bull, and Winzenberg 2012) and ensure adequate support and resources are available. Moreover, whilst it is important to recognise the value of parents' knowledge, there is still a need for information and education to support them to fulfil this role (Wolfendale 2002). As De Geeter and colleagues suggest,

'The logical assumption that parents know their child best does not imply that information concerning resources, the most appropriate form of therapy, the most suitable living environment or the most appropriate daily activities is readily available to them.'

De Geeter, Poppes, and Vlaskamp (2002: 444).

\section{Control of information}

Traditionally, provision of health-related information has been the domain of the health professional, with patients, or parents of patients, being passive recipients of knowledge (Kangas 2002). Historically, this approach has been reported to be highly valued by parents (Pain 1999); however, over the past 20 years, with the rapid emergence of the world wide web, service users at all levels of society are increasingly gaining access to a vast supply of unmetered health-related information (Benigeri and Plyue 2003). This means that controlling the content and flow of information can no longer be the exclusive remit of the health professional.

Since early in the twenty-first century, there has been a record of parents of children with disability meeting in support groups (Law et al. 2001) and, whilst it is generally accepted that the primary function of these groups is to provide a sense of belonging, support and advocacy, it is almost without exception that provision of information is highlighted as an important group function (Law et al. 2002, Solomon, Pistrang, and Barker 2001). It has been found that families will report that the information they receive from support groups is often more useful than that received from experts (Law et al. 2002) and it has been suggested that this is likely due to the fact that it is presented in a context which is more accessible (i.e. lay terminology, related to specific problems, non-threatening environment) (Solomon, Pistrang, and Barker 2001).

The conflict between free market information and controlled market healthcare offers a significant challenge to healthcare professionals, requiring a subtle shift from being information providers to information brokers. Interestingly there appears to be a lack of evidence regarding 
how health professionals perceive the loss of gate keeping of information and how this affects their practice.

\section{Timing of information}

Health professionals need to ensure that, when providing information, parents are able to readily understand and make use of it; however the complex nature of the parent's uncertain circumstances can be the source of a number of potential barriers for effective information exchange. For example, at the time of diagnosis, parents will typically experience very strong emotions including fear, guilt, anger and powerlessness (Nuutila and Salanterä 2006), and it is accepted that, at this early stage, the incompatibility between emotional distress and optimal learning is unavoidable (Jedlicka-Köhler, Götz, and Eichler 1996). This difficulty is reflected in reports that there is frequently a significant discrepancy between information given and information understood (Reid et al. 2011), with parents often reporting dissatisfaction with the amount of information provided (Graungaard and Skov 2007, Hummelinck and Pollock 2006).

There appears to be a lack of agreement in the literature regarding parents' preference for information at this time. Some parents report that it is best not to be given information around the time of diagnosis as they are unable to take it in (Kendall et al. 2003); whereas others suggest that they want information immediately following diagnosis (Tipping, Scholes, and Cox 2010). Furthermore there appears to be a gap in the literature related to health professionals' experiences of timing information provision to parents.

\section{Health professionals' approach to the provision of information}

It appears that there has been little work completed investigating how health professionals approach the complex process of providing information to parents. One qualitative study by Ringnér, Jansson and Graneheim (2011) used focus groups involving 20 caregivers on a paediatric oncology ward to investigate health professionals' perceptions of providing information to parents. Their findings suggested that health professionals did recognise that parents' need for information could change over time, and that the amount of information provided should be matched to the level of parental need. There was, however, no reference to how the health professionals identified this level of need, nor to any strategies they used to ensure appropriate information was given.

Other studies have investigated the phenomenon of recognising parent (or patient) need for information; however, there have been conflicting reports as to how successfully this has been managed (Hoffman et al. 2007, Hutchinson et al. 2012, McClinchy et al. 2011).

The gaps in the literature described form the basis of the current study, which addresses the research question: 'What are the views and experiences of health professionals as providers of information to parents of children with long term disabilities?' The aim was to generate new perspectives, inform debate, and to identify any practical suggestions for health professionals. The findings and discussion have generated suggestions for practice-based learning; however this was not necessarily pre-planned.

\section{Methodology}

This study adopted a qualitative approach guided by a phenomenological methodology. The rationale for choosing a phenomenological methodology was based on the underpinning philosophical assumptions of the constructivist paradigm that informs it (relativist ontology; subjectivist epistemology) (Nicholls 2009a). This study did not set out to prove or disprove any hypothesis; rather it sought to generate data from the lived experiences of health professionals in order to gain a greater understanding about how they perceive the phenomenon of information provision. 
The study was undertaken using semi structured interviews of a purposive, convenience sample of seven health professionals working in a single Children and Young Person's Therapy Service in the UK (two physiotherapists, two occupational therapists, and three speech and language therapists). All participants were working supporting children with a variety of lifelong disabilities, contributing to delay in one or more areas of their development. Examples included global developmental delay, specific motor dysfunction (e.g. cerebral palsy, neuromuscular dysfunction) and other more pervasive developmental disorders (e.g. autism). Literature supports that, given the heterogeneity of the participants, a sample size of seven is sufficient to achieve sampling sufficiency (Nicholls 2009b).

Interviews took the form of asking participants to reflect upon, and describe, their experiences of giving health-related information to parents. Subsequent questions followed the responses of the interviewees (i.e. when it worked well, when it did not work so well and what might have influenced this). The aim was to gain as complete a description as possible of the experience of the participants (Englander 2012).

It is important to state that the principal researcher worked in the same team from which the participants were recruited. Potential coercion and power issues were formally addressed by employing indirect recruitment strategies (i.e. participants were not approached personally, but with posters shared at team meetings giving contact details for those wishing to participate), by providing a detailed participant information sheet, and also by making explicit that participation in the study was voluntary. Informed consent was given by each participant. Further strategies were also employed as part of a process of reflexivity (discussed in detail below).

Ethical approval was granted by the relevant research ethics and governance panel at the sponsoring institution. The study was also approved by the Caldicott Guardian of the healthcare organisation as a 'grey area' project (the Caldicott Guardian is a senior member of the organisation responsible for protecting confidentiality of patient and service user information).

\section{Analysis of data}

Interviews were transcribed verbatim and then analysed using a rigorous, systematic process of thematic content analysis as described by Braun and Clarke (2006). This iterative process generated a number of initial themes, which were reviewed and further refined using a thematic mapping approach to produce two main themes, the first with two subthemes. It is acknowledged that a third theme 'Relationship with parents' was also identified, which will be presented and discussed in another article.

I (JR) addressed scientific rigour and trustworthiness by using the strategies suggested in the literature (Nicholls 2009b, Shenton 2004). An audit trail of data analysis, and a reflective log of the research process were kept to maintain transparency, and regular debriefings with my project supervisor (JM) were held to enhance credibility of findings.

\section{Reflexivity}

As the principal researcher, I (JR) was responsible for collecting and analysing all data. Whilst this process was supported by my project supervisor (JM), I felt it was important to include a reflexive statement in order to clearly state my positionality as an 'insider researcher' (Moore 2012), and how this and other experiences have informed and shaped the 'forestructure' of my understanding of the phenomena (Kumar 2012). This was felt to be especially important as the confirmability of my interpretations is dependent on my being able to demonstrate how they were reached (Mauther and Doucet 2003, Shenton 2004). 
Reflexive Statement (JR):

I qualified as a chartered physiotherapist BSc (Hons) in 2002 and have been working with children and their families since 2004.

Throughout my career thus far I have endeavoured to understand as clearly as possible the way that children develop and how this might be affected by different injury or impairment. This has informed the way I work and I feel that I have been able to offer a sound, evidenced based practice to the children that I support. Despite this, over the last few years, I have found myself becoming a little disillusioned with the service I have been able to offer. Whilst I could clearly justify my treatment strategies, I found that often families would not engage and that children were not making the progress that I had hoped they would. I started to reflect on this and began contemplating what might be affecting parental engagement with therapy.

Around this time I also became a father myself. This, more than any other specific event, has changed the way that I practise, more profoundly than I could have expected. It has helped me to empathise with parents and to understand that supporting children with movement disorders was far more complex than just choosing the right handling technique. I developed the opinion that it was essential to listen to parents' wishes and needs, and to help them to make therapy fit and work in their lives. Whilst my interest in identifying and understanding the impairment did not wane, managing this was now placed in the context of the lives of the child and their family. I now feel that when providing information to parents, it should be done in a very sensitive way, acknowledging their stage of acceptance and respecting their views and opinions.

Currently I am working as a highly specialised children's physiotherapist (Band 7) in an integrated child therapy team (the same team from which the participants in the current study were recruited). Being a band 7 carries with it certain responsibilities for team development and clinical support and as such I am regarded by some of my colleagues as a 'specialist/expert' therapist. I have been working in my current post for 5 years and during that time have established strong relationships with my colleagues. These relationships are generally professional; however there is also a significant degree of familiarity and friendship.

I acknowledge that my position as a 'specialist' member of the team from which participants were recruited, may have introduced a hierarchical imbalance between interviewer and interviewee, which in turn may have had an effect on what the participants were prepared to share. It is also likely that this imbalance may have been intensified by the fact that I had been conspicuously immersed in further education and training.

As well as the formal strategies described in the methodology, I endeavoured to conduct the interviews sensitively, ensuring that participants felt comfortable and relaxed at all times. Furthermore I made particular effort to avoid being judgemental respecting the participants' comments as valid representations of their views and opinions. The assurance of confidentiality was also brought to the fore in order to encourage openness. It was also hoped that my familiarity with the participants would have helped them to feel at ease and more willing to share their true feelings.

\section{Findings}

The findings are presented with quotations taken directly from the interview transcripts. Each quotation is written with an identifier, which represents the participant's profession (e.g. OT1 occupational therapist; PT1 - physiotherapist; S1 - speech and language therapist).

\section{Main theme 1: Readiness for information}

This theme describes participants' experiences of how a parent's need for information can change over time and how this need can be influenced by a number of factors. It has been 
broken down into two subthemes; firstly describing how participants feel this readiness for information can be recognised, defined as 'assessing parent readiness', and secondly how participants feel parents can be supported to become more ready, defined as 'developing parent readiness'.

\section{Subtheme $1 A-$ Assessing parent readiness}

All participants recognised that there was a need to be sensitive to parents' readiness for information and highlighted the importance of giving information at the right time.

...I think you have to time your information really carefully...even if you want the parents to have an eye on the future; you have to be mindful that this is their present. (OT1)

It was also suggested that providing information at an inappropriate time could have a potentially negative impact both on a parent's ability to engage with the information;

...they are too overwhelmed (by the information) and they are not actually listening to it, or that the information is just sort of washing through them rather than going in. (PT2)

and on the parent-therapist relationship;

...the OT had started to introduce equipment and the mum just completely wasn't able to accept it at that time and requested another OT... (OT2).

Despite recognising the importance of giving information at the appropriate time, participants found it difficult to identify clear indicators that parents were ready for the information, and felt that it came down to a kind of professional judgement or instinct, which was developed through experience rather than through formal training.

...it's a judgement call, you have to make a judgement call...I think it just comes with experience and it's a steep learning curve. (S1)

I haven't been given any training on how to present information...you just pick it up and go on instinct... you are basically lead by your own instinct... (PT2)

Some subtle, non-verbal indicators for lack of readiness were highlighted, including behaviours such as zoning out, panicking, crying and looking puzzled.

...they may just nod at you... and look like they are listening, but actually they are closed off... and you can tell the difference in their facial expressions...that the information is not being absorbed or that they are not ready for it... (PT2)

There was one participant who reported that parents would actually state their lack of readiness.

...so I have had a number of people (parents) saying to me, 'People (professionals) are saying to me that they (my child) are like this...l'm not ready to look at that yet'... (S2)

More commonly this was not so explicit, and participants reported that parents would continue to ask for information even though health professionals felt that they might not be ready to take on and make use of that information.

...even though they (parents) might say 'I want as much information as possible'...you know, they might remember some key things, but they won't necessarily remember everything...sometimes families say they want as much information as possible, but sometimes I don't actually think they do...(PT3) 
...some parents want to know everything about everything...; however they maybe don't want to hear the information that we give... (OT1)

Some participants recognised this paradox, of parents asking for information but only really wanting to hear what supported their own construct of their child's difficulties, and linked it to a denial or lack of acceptance of the true extent of the nature and impact of their child's condition.

...I guess that sometimes there will be some denial and you will get the real, 'well no, he's going to walk and he's going to sit up' and that's... well you don't want to encourage that... (OT2).

It was also highlighted that parents' readiness for information could be affected by setbacks, described by some participants as 'transition points' where the child's needs are changing.

...I think that you notice that there are certain...kind of...not milestones...but there are certain periods of time which almost affect a transition into accepting the future...(for example) talking about wheelchairs...that is a real, 'this is the future'... It think that can be quite challenging... (OT2)

When parents were more ready for information, participants noticed a number of changes in their behaviours; including asking more thoughtful/relevant questions, having more realistic expectations, taking more openly about the future and also a change in how they practically support their child.

...it's not always about them saying the right things, but I think if you...go into the room and they have done it (the handling technique) without you having to prompt them. I think that is a good way of seeing... (PT3)

\section{Subtheme 1B-Developing parent readiness}

All participants reflected on strategies they employed, either consciously or subconsciously, to try to help parents develop, or become more ready, to receive and make use of information about their child. One strategy was to drip feed information all the time, avoiding giving 'too much' information and avoiding 'bombshells'.

"...I think that kind of drip feeding the information works well...giving little bits of information at an appointment and then the next time building on that...so not giving everything all at once..." (PT2)

It was generally accepted that information should be clear, positive and relevant to the child; focusing on management of difficulties rather than on a label or diagnosis.

...so there is a lot of information to give isn't there and I think there is something in a skill of only giving what is relevant... (OT1)

...you have to begin with a list of things that are that person's strengths...it's my opinion that it's not so much about the label but what's done with it... (S3)

Several participants felt that taking a team approach was useful to address parents' readiness for information.

....if I didn't think the parents were ready for that information, I would speak to the team to arrange a time and that we would need to let them know... (OT1)

Participants also experienced that parents could be supported to become more ready for information by being made to feel secure and less anxious and this could be achieved by 
offering appointments in their homes, ensuring they are listened to, and by fostering a trusting relationship.

...I think if you do it (give the information) at home it is better...I just think people are more relaxed in their own environment... and having someone that you feel is being listened to....as in the therapist is listening to you as a parent... (PT3)

One interesting dilemma described by the participants was whether or not to withhold potentially difficult or upsetting information. Two of the participants felt that it was never appropriate to withhold information, whilst the others felt that it was often prudent to delay giving difficult information. One participant felt strongly that it can be very destructive to give parents difficult information, and spoke about not taking away hope.

"...I think the focus of your information has to be on what you feel the parents are able to take on board...or cope with...I don't withhold information though..." (OT1)

"... One thing that holds with me is that you don't want to take away hope...there is some research out there with evidence to suggest that vocabulary levels at 4 will dictate outcomes at GCSE (General Certificate of Secondary Education - public examinations for pupils aged 16$)$... but that seems like a fairly destructive message to give at 4 , when they are only just thinking about putting their child into school...I mean, I just think I might increase suicide rates or something..." (S2).

\section{Main theme 2: Role as information manager}

This theme describes participants' experiences of managing information available to parents, in particular how they feel about information which they did not control.

Participants described that parents now have access to a mass of information that is unregulated. The internet and social media was specifically highlighted as a problem.

...signposting people to the internet...that's a whole can of worms... (OT1)

It was recognised that, as the child's therapist, there was a role for managing this kind of information. This might involve preparing the parent for what they might find...

...l'll say, 'you may Google that, but if you do I want you to be aware that it might look a lot worse than I'm thinking about'...l'll kind of say you need to be careful where you look... (S2)

... or actively signposting parents to useful, more regulated websites.

...I think I would be particularly encouraging parents to specific, recognised websites, of which I have one or two that I think are very, very good... (S3)

"I would just have the discussion with them about being cautious what they read and also to point them in the right direction of good sources of information..." (PT3)

Some participants took a pragmatic view and felt that, when parents looked for information independently, it promoted discussion and better engagement with therapy.

...it really challenges you and it is really helpful...it makes you think about what you are doing and make sure your clinical reasoning is sound and that you are basing it on the right things, rather than just, 'this is what I always do for this'... (OT2)

...there's so much stuff out there...we don't know everything...so sometimes it's learning off parents...they'll say, 'I looked at this and bought it off whatever...' and you're kind of...'that would be really good'... (S2). 


\section{Discussion}

These findings highlight the perceived complexities faced by health professionals when attempting to both assess and develop parents' readiness for information.

The interesting observation that parents will often ask for information, even if they are not ready for it, is in contrast to the earlier findings of Pain (1999), who reported that the act of seeking information is a strong indicator of parental readiness. The perception that a parent's request for information is unreliable as an indicator of readiness is more in line with the findings of Hummelinck and Pollock (2006). They found that whilst parents sometimes requested all information about their child's difficulties, they would often not really be ready to engage with it. It is possible that this paradox is related to the parents' motive for seeking information. For example, it has been recognised that parents will often seek out information as a coping strategy when coming to terms with their child's difficulties; to feel more empowered and in control of their situation (Graungaard and Skov 2007, Pain 1999, Taanila et al. 2002).

It might be reasonable to assume that increased cognisance of this phenomenon is likely to support health professionals to become more aware of the way parents are engaging with information (i.e. to the subtle changes in behaviour and discourse described by the participants). Interestingly, participants felt that the way they responded to these parental cues was guided largely by professional judgement or instinct, and it was the consensus that these skills were not formally taught, rather that they were developed through experience. These findings concur with Caladine (2013), who also identified that health professionals felt their skills as 'patient educators' were more typically developed through professional experience rather than formal training.

It is possible that the perceived lack of formal training for health professionals, related to recognising and developing parent readiness for information, is due to the complexity and potential for diversity involved in these transactions. It is understandable that this level of ambiguity may not lend itself to a structured, specific training package. However, the process of having an 'experience' and then reflecting on that experience to change and develop practice is well recognised as a valuable learning strategy, set out by David Kolb (1984) as 'Kolb's Experiential Learning Theory'.

Engaging in more thoughtful, structured reflection on experiences of developing parent readiness may help health professionals to feel more confident and better equipped during these complex transactions. It may also be useful for health professionals to engage in peerassisted learning opportunities (Hammond et al. 2010), sharing and reflecting on their experiences, developing communities of practice/learning (Wenger 1998).

Whilst participants recognised the need to be sensitive to parents' state of readiness for information, they conceded that they were not able to maintain control over which information parents accessed. Despite this, they were able to offer some opinions about how this might be managed. Participants felt that parents' unmetered access to information, on the internet in particular, could be the source of some difficulties. Despite this, they recognised that taking a proactive approach, preparing parents for the information they might encounter, or by signposting them to more regulated websites, was a strategy that helped them retain a degree of control over the information that parents accessed.

Some participants were able to take a more positive, pragmatic view and recognised that if parents were more active in searching out information independently it actually promoted useful discussion and engagement with therapy. This is in line with the findings of Hardey (1999), who found that independently researched information equips patients (and parents) with resources they need to engage in a more reflexive evaluation of the information supplied by the health professional. Other literature describes a less positive finding, whereby some parents referred to information they have sourced independently as "ammunition" to fight "battles" against professionals (Solomon et al. 2001: 122). 
This apparent variation in parental approach to the 'use' of independently sourced information may be due to the context in which that information is being sought. It seems, on one hand, to reflect a positive, engaged parent behaviour, and on the other a more negative, combative attitude. It is possible that the health professional's opinion on parent's practice of independent research may have a direct influence on parental mind-set. Whilst this was not explicit in the findings of this study, it does raise a question about best practice in promoting/managing parental use of independently sourced information.

One perspective is that health professionals may benefit from support to adapt their approach to parent education; shifting attention from the content of the information they provide, and even to some extent from how/when information is given, to focus more on how a parent is engaging with information. This line of thought draws interesting parallels with Meyer and Land's 'Threshold Concepts' in education (Meyer and Land 2003). These authors suggest that the educator (in this case the health professional) should be invested in the learning of the students (in this case the parents), rather than in just the transfer of information. They explain that a threshold concept represents a significant transformation in how something is viewed or understood, without which progress in understanding cannot be made. The identification of what represents a threshold concept for parents of children with disabilities (related to how they engage with information) may support health professionals to take a more proactive, informed approach in developing parental readiness.

This suggestion also resonates with the shared decision-making model of healthcare described by Edwards, Davies and Edwards (2009). These authors suggest that information exchange (which is the prerequisite for shared decision-making) can be facilitated by improving service users' ability to access information and, more importantly, to critically assess its quality. It may be that improving health literacy, by focusing on how parents are engaging with information, will also help to ensure parents make use of the information in a more positive way.

\section{Implications for practice and learning:}

- Health professionals working in this context may benefit from exploring opportunities for development of practice-based learning initiatives, to share and reflect on experiences of providing information to parents. The value of both experiential learning and peerassisted learning as valid learning/CPD activities should also be highlighted.

- It may be useful for health professionals to consider their approach to parent education, specifically how they can best support parents to develop as learners. Further research into what might represent a threshold concept for parents when engaging with information from health professionals is recommended.

- It is suggested that health professionals should consider proactively encouraging parents to independently research information about their child's condition and embrace the resultant opportunities to engage in discussion. The benefits of such practice are likely to extend beyond simply improving parental engagement with information, and may include opportunity for health professionals to reflect on their clinical decision making. The views of the participants in this study suggest that this kind of paradigm shift may not sit comfortably with all health professionals, and it is recommended that further investigation be carried out to determine how such a practice may be implemented successfully.

- Given the perceived lack of formal training related to information provision (in particular providing difficult/upsetting information), it may be valuable for higher education institutions to consider how to make this part of the curriculum more explicit.

\section{Limitations}

This was a small-scale qualitative study based on interviews with health professionals from a single team. The findings are therefore not generalisable; however this was not the intention of 
the study. Generating an understanding of relevant issues and exploring how this understanding may influence practice, and guide future research, was the goal.

All participants were self-selecting volunteers; as such, the sample may not be truly representative of the group being investigated. Furthermore, all participants were known to the researcher as colleagues and peers, which may have influenced their discourse (either positively or negatively). Despite these concerns, it is considered that data collection and analysis was conducted employing a suitably rigorous and reflexive method, such that the impact of such relationships was recognised and embraced.

It is recognised that the sample of participants in this study did not include representation of all health professionals whose role includes providing information to parents; most notably, no paediatricians were interviewed.

To improve the collection of data in this study, it may have been valuable to have explored the potential for group interviews/focus groups, as well as individual interviews. This would have given opportunity for point/counter point discussion and resolution, and also for drawing out more latent issues, improving the credibility of the findings.

To further improve the study design, it may have been helpful to include observations/video recordings of health professional - parent interactions, providing a potentially useful comparison between health professionals' rhetoric and their espoused/actual practice. It would also have been useful to interview parents of children accessing the service. Analysis of data from health professionals alongside data from parents may have revealed an even deeper insight into the phenomenon, and could form the basis for further study.

\section{Conclusions}

The findings of this study suggest that the health professional's role as a provider of information to parents of children with disabilities is evolving. It may be that this role may now be more helpfully described as a parent educator, involving a shift in focus from content/timing of information provision to the development of parents as learners. Furthermore, it is suggested that actively promoting parents to research health-related information about their child may help to open a positive dialogue and improve engagement with information provided by health professionals.

It is also suggested that it would be useful for health professionals to explore opportunities for practice-based initiatives to support the development of the skills required for this role.

\section{Acknowledgements}

We wish to acknowledge the support offered by the hosting healthcare organisation. The organisation is not named as it was felt this might compromise participant anonymity. 


\section{References}

Benigeri, M. and Pluye, P. (2003) 'Shortcomings of health information on the internet'. Health Promotion International 18 (4), 381-386. doi: 10.1093/heapro/dag409

Braun, V. and Clarke, V. (2006) 'Using Thematic Analysis in Psychology'. Qualitative Research in Psychology 3 (2), 77-101. doi: 10.1191/1478088706qp0630a

Caladine, L. (2013) 'Physiotherapists construction of their role in patient education'. The International Journal of Practice-Based Learning in Health and Social Care 1 (1), 3749. doi: $10.11120 /$ pblh.2013.00005

De Geeter, K. I., Poppes, P., and Vlaskamp, C. (2002) 'Parents as experts: The position of parents of children with profound multiple disabilities'. Child: Care, Health and Development 28 (6), 443-453. doi: 10.1046/j.1365-2214.2002.00294.x

Edwards, M., Davies, M., and Edwards, A. (2009) 'What are the external influences on information exchange and shared decision making in healthcare consultations: A metasynthesis of the literature'. Patient Education and Counselling 75 (1), 37-52. doi: 10.1016/j.pec.2008.09.025

Englander, M. (2012) 'The interview: Data collection in descriptive phenomenological human scientific research'. Journal of Phenomenological Psychology 43, 13-35. doi: $\underline{10.1163 / 156916212 \times 632943}$

Graungaard, A. H, and Skov, L. (2007) 'Why do we need a diagnosis? A qualitative study of parents' experiences, coping and needs, when the new-born child is severely disabled'. Child: Care, Health and Development 33 (3), 296-307. doi: 10.1111/j.13652214.2006.00666.x

Great Britain Parliament (2014) Children and Families Act 2014. [Act of Parliament] available from http://www.legislation.gov.uk/ukpga/2014/6/contents/enacted

Hammond, J. A., Bithell, C. P., Jones, L., and Bidgood, P. (2010) 'A first year experience of student-directed peer-assisted learning'. Active Learning in Higher Education 11 (3), 201-212. doi: 10.1177/1469787410379683

Hanna, K. and Rodger, S. (2002) 'Towards family-centred practice in paediatric occupational therapy: A review of the literature on parent-therapist collaboration'. Australian Occupational Therapy Journal 49, 14-24. doi: 10.1046/j.0045-0766.2001.00273.x

Hardey, M. (1999) 'Doctor in the house: The internet as a source of lay health knowledge and the challenge to expertise'. Sociology of Health IIIness 21(6), 820-835. doi: $10.1111 / 1467-9566.00185$

Health and Care Professions Council (2016) Standards of conduct, performance and ethics. London: HCPC. available from: http://www.hpcuk.org/aboutregistration/standards/standardsofconductperformanceandethics/ [31 March 2016]

Hoffman, T., McKenna, K., Herd, C., and Wearing, S. (2007) 'Written education materials for stroke patients and their carers: Perspectives and practices of health professionals'. Topics in Stroke Rehabilitation 14 (1), 88-97. doi: 10.1310/tsr1401-88

Hummelinck, A. and Pollock, K. (2006) 'Parents' information needs about the treatment of their chronically ill child: A qualitative study'. Patient Education and Counselling 62, 228-234. doi: $10.1016 /$ j.pec.2005.07.006 
Hutchinson, C., Morrison, A., Rice, A. M., Tait, G., and Harden, S. (2012) 'Provision of information about malignant spinal cord compression: Perceptions of patients and staff'. International Journal of Palliative Nursing 18 (2), 61-68. doi: 10.12968/ijpn.2012.18.2.61

Jedlicka-Köhler, I., Götz, M., and Eichler, I. (1996) 'Parents' recollection of initial communication of the diagnosis of cystic fibrosis'. Pediatrics 97 (2), 204-209.

Kangas, I. (2002) "Lay" and "expert": Illness knowledge constructions in sociology of health and illness'. Health: An Interdisciplinary Journal for the Social Study of Health IIIness and Medicine 6 (3), 301-304. doi: 10.1177/136345930200600303

Kendall, L., Sloper, P., Lewin, R. J. P., and Parsons, J. M. (2003) 'The views of parents concerning the planning of services for rehabilitation of families with congenital cardiac disease'. Cardiology in the Young 13, 20-27. doi: 10.1017/S1047951103000052

King, S., Teplicky, R., King, G. and Rosenbaum, P. (2004) 'Family-centred service for children with cerebral palsy and their families: A review of the literature'. Seminars in Pediatric Neurology 11 (1), 78-86. doi: 10.1016/j.spen.2004.01.009

Kolb, D. A. (1984) Experiential learning: Experience as the source of learning and development Englewood Cliffs, NJ: Prentice-Hall

Kratz, L., Uding, N., Trahms, C. M., Villareale, N., and Kieckhefer, G. M. (2009) 'Managing childhood chronic illness: Parents' perspectives and implications for parent provider relationships'. Families, Systems and Health 27 (4), 303-313. doi: 10.1037/a0018114

Kumar, A. (2012) 'Using phenomenological research methods in qualitative health research'. International Journal of Human Sciences 9 (2), 790-804.

Law, M., Hanna, S., King, G., Hurley, P., King, S., Kertoy, M., and Rosenbaum, P. (2003) 'Factors affecting family centred service delivery for children with disabilities'. Child: Care, Health and Development 29 (5), 357-366. doi: 10.1046/j.13652214.2003.00351.x

Law, M., King, S., Stewart, D. and King, G. (2002) 'The perceived effects of parent led support groups for parents of children with disabilities'. Physical and Occupational Therapy in Pediatrics 21 (2/3), 29-48.

Leiter, V., Wyngaarden Krauss, M., Anderson, B., and Wells, N. (2004) 'The consequences of caring. Effects of mothering a child with special needs'. Journal of Family Issues 25 (3), 379-403. doi: 10.1177/0192513X03257415

Mauthner, N. S. and Doucet, A. (2003) 'Reflexive accounts and accounts of reflexivity in qualitative data analysis'. Sociology 37 (3), 413-431. doi: $10.1177 / 00380385030373002$

McCann, D., Bull, R., and Winzenberg, T. (2012) 'The daily patterns of time use for parents of children with complex needs: A systematic review'. Journal of Child Health Care 16 (1), 26-52. doi: $10.1177 / 1367493511420186$

McClinchy, J., Dickinson, A., Barron, D., and Thomas, H. (2011) 'Practitioner and lay perspectives of the service provision of nutrition information leaflets in primary care'. Journal of Human Nutrition and Dietetics 24, 552-559. doi: 10.1111/j.1365277X.2011.01200.x 
Meyer, J. and Land, R. (2003) Threshold concepts and troublesome knowledge: Linkages to ways of thinking and practising within the disciplines. Edinburgh: University of Edinburgh

Moore, J. (2012) 'A personal insight into researcher positionality'. Nurse Researcher 19 (4), $11-$ 14. doi: $10.7748 / \mathrm{nr} 2012.07 \cdot 19.4$.11.c9218

Nicholls, D. (2009a) 'Qualitative research: Part one - Philosophies'. International Journal of Therapy and Rehabilitation 16 (10), 526-533. doi: 10.12968/ijtr.2009.16.10.44562

Nicholls, D. (2009b) 'Qualitative research: Part two - Methodologies'. International Journal of Therapy and Rehabilitation 16 (11), 586-592. doi: 10.12968/ijtr.2009.16.11.44939

Nuutila, L. and Salanterä, S. (2006) 'Children with a long-term illness: Parents' experiences with care'. Journal of Pediatric Nursing 21 (2), 153-160. doi: 10.1016/j.pedn.2005.07.005

Pain, H. (1999) 'Coping with a child with disabilities from the parents' perspective: The function of information'. Child: Care, Health and Development 25 (4), 299-312. doi: 10.1046/j.1365-2214.1999.00132.x

Reid, A., Imrie, H., Brouwer, E., Clutton, S., Evans, J., Russell, D., and Bartlett, D. (2011) 'If I knew then what I know now": Parents' reflections of raising a child with cerebral palsy'. Physical and Occupational Therapy in Pediatrics 31 (2), 169-183. doi: $10.3109 / 01942638.2010 .540311$

Ringnér, A., Jansson, L., and Graneheim, U. H. (2011) 'Professional caregivers' perceptions of providing information to parents of children with cancer'. Journal of Pediatric Oncology Nursing 28 (1), 34-42. doi: 10.1177/1043454210377175

Rosenbaum, P., King, S., Law, M., King, G., and Evans, J. (1998) 'Family-centred service: A conceptual framework and research review'. Physical and Occupational Therapy in Pediatrics. 18, 1-20. doi: 10.1080/j006v18n01_01

Shenton, A. K. (2004) 'Strategies for ensuring trustworthiness in qualitative research projects'. Education for Information 22, 63-75.

Solomon, M., Pistrang, N., and Barker, C. (2001) 'The benefits of mutual support groups for parents of children with disabilities'. American Journal of Community Psychology 29 (1), 113-132. doi: 10.1023/A:1005253514140

Taanila, A., Syrjälä, L., Kokkonen, J., and Järvelin, M. -R. (2002) 'Coping of parents with physically and or intellectually disabled children'. Child: Care, Health and Development 28 (1), 73-86. doi: 10.1046/j.1365-2214.2002.00244.x

Tipping, C. J., Scholes, R. L., and Cox, N. S. (2010) 'A qualitative study of physiotherapy education for parents of toddlers with cystic fibrosis'. Journal of Cystic Fibrosis 9, 205211. doi: $10.1016 /$ j.jcf.2010.02.003

Tourigny, J., Chartrand, J., and Massicotte, J. (2008) 'Health professionals' beliefs related to parental involvement in ambulatory care: An international inquiry'. Issues in Comprehensive Pediatric Nursing 31, 89-101. doi: 10.1080/01460860802023539

Wenger, E. (1998) Communities of Practice. Learning, Meaning and Identity. Cambridge: Cambridge University Press doi: 10.1017/CBO9780511803932 
Wolfendale, S. (2002) 'Standard-bearing: Assuring quality in parent partnership services'. Paper presented at the National Network of Parent Partnership Services Conference, 28 February 2002, Britannia Hotel, Birmingham

World Health Organization (2001) International Classification of Functioning, Disability and Health (ICF). Geneva: WHO 